\title{
Investigating the Effectiveness of Dialectical Behavior Therapy in Clinical Symptoms, Anger Control and Emotional Regulation of Bully Children
}

\author{
Fereshteh Partoiy Ziraki1, Toozandehjani Hassan ${ }^{2 *}$ \\ ${ }^{1}$ MA in Counseling,, Department of Psychology, Faculty of Humanities, Neyshabur Branch, Islamic Azad University, Neyshabur, \\ Iran \\ ${ }^{2}$ Assistant Professor of Psychology, Department of Psychological Sciences, Faculty of Humanities, Neyshabur Branch, Islamic \\ Azad University, Neyshabur, Iran \\ Email: ${ }^{\star}$ H.Toozandehjani@ymail.com
}

How to cite this paper: Ziraki, F.P. and Hassan, T. (2017) Investigating the Effectiveness of Dialectical Behavior Therapy in Clinical Symptoms, Anger Control and Emotional Regulation of Bully Children. International Journal of Clinical Medicine, 8, 277-292.

https://doi.org/10.4236/ijcm.2017.84027

Received: February 24, 2017

Accepted: April 27, 2017

Published: April 30, 2017

Copyright $\odot 2017$ by authors and Scientific Research Publishing Inc. This work is licensed under the Creative Commons Attribution International License (CC BY 4.0).

http://creativecommons.org/licenses/by/4.0/

\begin{abstract}
The present study aims to investigate the effectiveness of dialectical behavior therapy in clinical symptoms, anger control and emotional regulation of bully children. This research is a pretest-posttest quasi-experimental study design with a nonequivalent control group. The research sample comprises 24 bully children who were purposefully selected from among the students who had responded positively to the researcher's call. The participants were randomly assigned into two experimental and control groups. Group therapy intervention was conducted on the experimental group during ten sessions. The tools applied in this study consisted of Cognitive Emotion Regulation Questionnaire by Garnefski et al., State-Trait Anger Expression Inventory by Spielberger and Bullying Scale by Illinois, Espelage and Holt and the subjects answered to their questions in the stage of pretest and posttest. In this research, the data was analyzed based on the analysis of covariance test and with the aid of SPSS software. The findings demonstrated that dialectical behavior therapy has a significant impact on clinical symptoms, anger control and its components and emotional regulation and its components $(\mathrm{P}<0.01)$.
\end{abstract}

\section{Keywords}

Dialectical Behavior Therapy, Clinical Symptoms of Bullying, Anger Control, Emotional Regulation

\section{Introduction}

Bullying at schools has been currently raised as a global and important problem 
in the field of psychology and public health [1]. It is one of the problematic behaviors that has recently attracted the attention of different researchers especially educational psychologists, educational researchers, teachers and parents around the world [2]. Bullying is a deliberate aggressive or annoying behavior that is repeatedly applied by a group or an individual in a period of time and includes the imbalance of power and appears in the form of physical, verbal and communicative behaviors [3]. Briefly, bullying can be defined as a negative deliberate action which is performed with the aim of inflicting physical or psychological injuries on other weaker students who cannot defend themselves [4]. Bullying at school has been considered as a serious personal, social and educational problem which has affected a considerable portion of school students. Effective control of the problem of bullying for school has high priority as much as the school has the responsibility of providing a healthy environment for students so that they learn constructive participation in society [5].

Bullying in boys is three times as much as girls and has been reported to be more severe in early adolescence (11 - 14 years). Bully boys usually annoy both girls and boys, but bully girls do not bully the people of their own sex. Bullying often becomes effective and the victims are from every stratum in terms of age, gender, education and social class; thus, it persists [6].

Bullying is a form of violence which threatens the well-being of adolescents and young people in schools and neighborhoods and may lead to feelings of low self-esteem, fear and humiliation of youths by the aggressive actions of other young people [7]. Bullying people with internalizing disorders have multiple problems including depression, suicidal thoughts, psychosomatic symptoms and feelings of tension and fatigue and bullying individuals with externalized disorders often engage in hyperactive, criminal and aggressive behaviors [7]. [8] has defined anger as a natural emotion and considers it to be severe discomfort and emotional response to the evaluated stimulation. Anger control is one of the issues that has long been raised in the field of psychology.

By anger control skills in this study, it means the skills that Klinke introduced in 1998 to cope with anger and includes the use of social protection systems, problem-solving skills, relaxation skills, skills to maintain internal control, humor skills, speaking skills and effective dialogue, listening skills and clear expression of one's feelings [9]. It can be briefly stated that anger control skill is a kind of cognitive behavioral therapy approach that aims to create changes in the cognition and behavior of individuals [9] and embraces the effective components in interpersonal relationships. For example, [10] conducted a study and assessed the efficiency of anger management skill in reducing the anger expression of patients with schizophrenia. They found that anger management training has been effective in reducing anger expression and increasing the ability to control anger among patients.

The aim of this study is investigating the effectiveness of dialectical behavior therapy in clinical symptoms, anger control and emotional regulation of bully children in Iran. 


\section{Literature Review}

In the following, it should be noted that along with these strategies, emotional regulation can be applied as an anger control skill since emotional regulation has a significant role in developing and maintaining emotional disorders [11]. Since anger is an emotion, emotional regulation can play a crucial role in the transformation of anger. Emotional regulation consists of any coping strategy which is used by individuals when faced with intense emotions [12]. Indeed, emotion regulation refers to the ability to understand emotions, modify the emotional experience and express emotions. Cognitive emotion regulation strategies help people regulate negative emotions and arousals [13]. Notably, difficulty in emotional regulation has been provided as a key component in several models of psychopathology for certain disorders. Disorders such as borderline personality disorder, major depression, bipolar disorder, generalized anxiety, social anxiety, eating disorders and disorders associated with drug and alcohol abuse are among the disorders in which the role of difficulties in emotional regulation has been examined and approved. With regard to what has been mentioned above, it can be said that deficit in emotional regulation can lead to hostile behaviors [14].

Hence, considering the importance of the component of emotional regulation in adjusting and controlling the emotion of anger, getting help from a therapeutic approachwhich can deal with emotional regulation is of great importance. Accordingly, dialectical behavior therapy (DBT) is one of the new therapeutic approaches whose effectiveness in emotional regulation is very promising [15].

Dialectical behavior therapy is a special kind of cognitive-behavioral psychotherapy which was developed by Marshall Linehan in the late eighties. Dialectical behavior therapy is a cognitive-behavioral approach which emphasizes the psycho-social aspects of treatment [16]. This treatment is an integrated treatment method in which the patient is taught to identify the contradictions within himself and those between himself and the environment and achieve an efficient result through combining and integrating them with each other. In this regard, [17] performed a study and investigated the effectiveness of dialectical behavior therapy with the reliance on the components of distress tolerance and emotional regulation in impulsive behaviors and explosive anger. They came to the conclusion that there is significant difference between the experimental and control groups after the implementation of dialectical behavior therapy in terms of the effect of distress tolerance and emotional regulation on the variables of impulsive behaviors and explosive anger. Ultimately, they stated that dialectical behavior therapy should be used as a helpful and efficient method in improving the inappropriate emotions. [18] observed that dialectical behavior group therapy can lead to improved aggressiveness, difficulties in emotion regulation, distress tolerance and mindfulness of aggressive adolescents.

Outside of Iran, studies have been conducted in this respect including the research done by [19]. In their article, they examined the influence of dialectical behavior therapy on reducing the impulsive behaviors of patients with borderline personality disorder and concluded that dialectical behavior therapy is a 
treatment which has a clear structure and uses behavioral techniques and includes dialectical principles and techniques such as self-observation, meditation, exposure and dependency contract. Training these behavioral techniques can help in decreasing the stability of disruptive behavior and impulse control disorders. In a study, [20] evaluated the effectiveness of dialectical behavior therapy in emotional regulation. They came to the conclusion that dialectical behavior therapy is a treatment designed particularly for the individuals who show selfinjurious behaviors such as self-injury, suicidal thoughts, desire to commit suicide and suicide attempts. [21] carried out a study and investigated the effectiveness of dialectical behavior therapy for depressed people. He revealed that the use of dialectical behavior therapy skills for the students with emotional dysregulation leads to enhanced management of their negative emotions.

According to the above-mentioned materials and with respect to the effect of dialectical behavior therapy on improving the emotions of individuals, this research seeks to answer the question as to whether dialectical behavior therapy is significantly effective in clinical symptoms, anger control and emotional regulation of bully children.

\section{Method, Population and Sample}

This research is an applied study in terms of purpose and a quasi-experimental study in terms of data collection method. Also, it is a pretest-posttest study design with a nonequivalent control group. The research statistical population comprises all the bully male students in the schools of District 4 of Mashhad in the academic year 2015-2016. The research statistical sample consists of 24 bully students who were selected from among the male students of District 4 in Mashhad and were assigned into two experimental and control groups (the students have been selected randomly). To this end, purposive sampling method was used. Of these 24 individuals, 12 people were put in the control group and 12 people in the experimental group through available sampling and studies and interventions were conducted only on the subjects of the experimental group for 10 sessions.

To collect the data in the present study, Cognitive Emotion Regulation Questionnaire by Garnefski, Kraaij and Spinhoven, State-Trait Anger Expression Inventory by Spielberger and Bullying Scale by Illinois, Espelage and Holt were applied.

1) Cognitive Emotion Regulation Questionnaire: This scale has been developed by Garnefski, Kraaij and Spinhoven to assess the cognitive strategies used by each individual after experiencing distressing events (events that cause a negative emotional state in the individual). The questionnaire includes 36 items and should be answered based on a graded Likert scale (never $=1$, always $=5$ ). It also consists of 9 subscales, each of which evaluates a specific cognitive strategy. The subscales include self-blame, blaming others, acceptance, refocus on planning, rumination, catastrophizing, positive refocusing, positive reappraisal and putting 
into perspective. Each scale comprises 4 items and the score of each subscale (in the range of 4 to 20) is obtained through adding the scores given to each item. The sum total of scores ranges from 36 to 180. In examining the test psychometric properties, [22] obtained the test reliability to be respectively $0.91,0.87$ and 0.93 using Cronbach's alpha coefficient. In Iran, the test validity was examined through the correlation between the total score and scores of the test subscales, which ranged from 0.40 to 0.68 with an average of 0.56 and all of them were significant. Moreover, in studying the questionnaire reliability, Cronbach's alpha coefficient was reported to be 0.82 [23].

2) State-Trait Anger Expression Inventory: This questionnaire is a pen and pencil scale which has 57 items and includes six scales and five subscales and its items have been organized into three parts. The first part with the title of "I feel right now" measures the state anger in which the subjects rate the intensity of their feeling based on a four-point scale ranging from "not at all $=1$ " to "very high $=4$ ". The second part with the title of "I usually feel" and 10 items evaluates the trait anger. The third part with the title of "I'm typically angry, what reaction or behavior I have" assesses anger expression and control and consists of four subscales which are composed of the following items: This part has been graded on a four-point scale ranging from "almost never $=1$ " to "always $=4$ " and embraces 32 items. a) anger expression-out (expressed) (AX-O): 27, 31, 35, 39, 43, 47, 51, 55; b) anger expression-in (repressed) (AX-I): 29, 33, 37, 41, 45, 49, 53, 57; c) anger control-out (AC-O): 26, 30, 34, 38, 42, 46, 50, 54; d) anger controlin (AC-I): $28,32,36,40,44,48,52,56$. In this questionnaire, based on the necessity of the research, we use dimensions of internal and external anger control. To calculate the reliability coefficients of each subscale, Khodayari-fard, GholamaliLavasani, Akbari Zardkhaneh and Liyaqat (2007) applied three methods of Cronbach's alpha, split-half and test-retest (with an interval of two weeks with $\mathrm{N}=60$ ) whose results for the two components of external and internal anger control are respectively $0.87,0.84,0.87,0.89,0.84$ and 0.87 .

3) Illinois Bullying Scale (IBS): Espelage and Holt designed this questionnaire. It has 18 questions which measure three subscales of bullying, fighting and victimization. This questionnaire is based on a five-point Likert scale ranging from never to seven times or more. In this questionnaire, a high score represents high levels of bullying and a low score indicates low levels of bullying in the individual. The score of each subscale is calculated by adding the scores of each relevant question. The highest score that an individual can obtain is 72 and the lowest score is zero. This questionnaire does not have reverse scoring. Espelage and Holt used Cronbach's alpha method to determine the questionnaire reliability, which alpha coefficient for the whole scale was obtained to be 0.83 and for the subscales of bullying, fighting and victimization, it was estimated to be respectively $0.87,0.83$ and 0.88 . In Iran, this scale has been standardized by Akbari Baloutbongan and Tale'pasand and Cronbach's alpha coefficient for the whole scale was obtained to be 0.87 and for the subscales of bullying, fighting and victimization, it was reported to be respectively $0.77,0.71$ and 0.76 . In their re- 
search, the first question of the questionnaire did not have good reliability and was excluded and therefore, the Persian version of this questionnaire was presented with 18 questions.

\section{Method of Implementation}

After a preliminary study and preparation of tools and referring to the Department of Education to get a license and giving a call to schools and getting their cooperation, the subjects were chosen. The samples were asked by a letter to cooperate regarding the study and were assured sufficiently that their information will remain confidential and will not be shared with others. After conducting the interventions on the experimental group, the questionnaires were collected and the data was analyzed. The educational content of the sessions was that initially, the beginning of each session was allocated to a summary of the previous session's discussions and study of the members' assignments. Objectives of the training sessions are as follows:

First session: Introduction of members, establishing communication, explaining the reason for group therapy and introduction of dialectical behavior therapy (DBT).

Second session: Training basic distress tolerance skills including distraction and self-relaxation.

Third session: Training advanced distress tolerance skills including the visualization of a safe place, discovery of values and confirmative self-talk.

Fourth session: Training basic mindfulness skills including practicing inattention.

Fifth session: Training advanced mindfulness skills including wise mind, fundamental acceptance, non-judgment and daily schedule of mindfulness.

Sixth session: Practicing for more examination of mindfulness and meditation.

Seventh session: Training basic emotional regulation skills including identifying emotions, reducing physical vulnerability in the face of turbulent emotions and reducing cognitive vulnerability.

Eighth session: Training advanced emotional regulation skills including encountering the emotion and acting on strong emotional desires and problem solving.

Ninth session: Training basic effective communication skills including learning skills and passive behavior against aggressive behavior.

Tenth session: Training advanced effective communication skills including presumptuous drafts, bold listening, saying no and method of negotiating.

\section{Data analysis Method}

The data obtained from the scores of this study is analyzed at two descriptive and inferential levels. At the descriptive level, indicators such as mean, standard deviation, frequency and percentage are used and at the inferential level, analysis of covariance method with the aid of SPSS22 software is applied. 


\section{Findings}

In this study, multivariate analysis of covariance test has been used due to its more suitability and compatibility with the research hypotheses. Before conducting the analysis of covariance test, three assumptions of normal distribution of scores, homogeneity of variances and covariance matrix consistency were investigated whose results have been provided in the following tables (Tables 1-3):

Kolmogorov-Smirnov test results in Table 1 demonstrate that the distribution of scores in all of the research components is normal since the significance level of Kolmogorov-Smirnov test has been obtained to be higher than 0.05 for all components. Therefore, the first assumption has been observed. The results

Table 1. Results of examining the normal distribution of the scores obtained from bullying clinical symptoms, anger control and emotional regulation.

\begin{tabular}{|c|c|c|c|c|}
\hline Variable & $\begin{array}{l}\text { Dimensions of the } \\
\text { variable }\end{array}$ & Test & $Z$ value & Significance level \\
\hline \multirow{6}{*}{$\begin{array}{l}\text { Bullying clinical } \\
\text { symptoms }\end{array}$} & \multirow{2}{*}{ Bullying } & Pretest & 0.692 & 0.724 \\
\hline & & Posttest & 0.724 & 0.672 \\
\hline & \multirow{2}{*}{ Fighting } & Pretest & 1.024 & 0.245 \\
\hline & & Posttest & 0.706 & 0.701 \\
\hline & \multirow{2}{*}{ Victimization } & Pretest & 0.892 & 0.404 \\
\hline & & Posttest & 1.000 & 0.270 \\
\hline \multirow{4}{*}{ Anger control } & \multirow{2}{*}{$\begin{array}{l}\text { External anger } \\
\text { control }\end{array}$} & Pretest & 0.568 & 0.903 \\
\hline & & Posttest & 0.768 & 0.597 \\
\hline & \multirow{2}{*}{$\begin{array}{l}\text { Internal anger } \\
\text { control }\end{array}$} & Pretest & 0.758 & 0.614 \\
\hline & & Posttest & 0.747 & 0.633 \\
\hline \multirow{18}{*}{$\begin{array}{l}\text { Emotional } \\
\text { regulation }\end{array}$} & \multirow{2}{*}{ Self-blame } & Pretest & 1.173 & 0.127 \\
\hline & & Posttest & 1.015 & 0.254 \\
\hline & \multirow{2}{*}{ Blaming others } & Pretest & 0.900 & 0.393 \\
\hline & & Posttest & 0.805 & 0.537 \\
\hline & \multirow{2}{*}{ Acceptance } & Pretest & 0.653 & 0.788 \\
\hline & & Posttest & 0.692 & 0.313 \\
\hline & \multirow{2}{*}{$\begin{array}{l}\text { Refocus on } \\
\text { planning }\end{array}$} & Pretest & 0.955 & 0.321 \\
\hline & & Posttest & 0.852 & 0.462 \\
\hline & \multirow{2}{*}{ Rumination } & Pretest & 0.702 & 0.708 \\
\hline & & Posttest & 0.701 & 0.709 \\
\hline & \multirow{2}{*}{ Catastrophizing } & Pretest & 0.894 & 0.401 \\
\hline & & Posttest & 0.958 & 0.318 \\
\hline & \multirow{2}{*}{$\begin{array}{l}\text { Putting into } \\
\text { perspective }\end{array}$} & Pretest & 0.834 & 0.490 \\
\hline & & Posttest & 1.017 & 0.252 \\
\hline & \multirow{2}{*}{ Positive refocusing } & Pretest & 1.104 & 0.175 \\
\hline & & Posttest & 0.716 & 0.685 \\
\hline & \multirow{2}{*}{ Positive reappraisal } & Pretest & 0.952 & 0.325 \\
\hline & & Posttest & 1.041 & 0.229 \\
\hline
\end{tabular}


Table 2. Results of examining the homogeneity of variances of bullying clinical symptoms, anger control and emotional regulation.

\begin{tabular}{|c|c|c|c|c|c|}
\hline Variable & $\begin{array}{c}\text { Dimensions of the } \\
\text { variable }\end{array}$ & Levene & $\begin{array}{l}\text { Degree of } \\
\text { freedom } 1\end{array}$ & $\begin{array}{l}\text { Degree of } \\
\text { freedom } 2\end{array}$ & $\begin{array}{c}\text { Significance } \\
\text { level }\end{array}$ \\
\hline \multirow{3}{*}{$\begin{array}{c}\text { Bullying } \\
\text { clinical } \\
\text { symptoms }\end{array}$} & Bullying & 0.158 & 1 & 22 & 0.695 \\
\hline & Fighting & 0.039 & 1 & 22 & 0.845 \\
\hline & Victimization & 0.719 & 1 & 22 & 0.406 \\
\hline \multirow{2}{*}{$\begin{array}{l}\text { Anger } \\
\text { control }\end{array}$} & $\begin{array}{l}\text { External anger } \\
\text { control }\end{array}$ & 2.760 & 1 & 22 & 0.111 \\
\hline & $\begin{array}{l}\text { Internal anger } \\
\text { control }\end{array}$ & 0.270 & 1 & 22 & 0.608 \\
\hline \multirow{9}{*}{$\begin{array}{l}\text { Emotional } \\
\text { regulation }\end{array}$} & Self-blame & 0.660 & 1 & 22 & 0.425 \\
\hline & Blaming others & 0.247 & 1 & 22 & 0.624 \\
\hline & Acceptance & 1.135 & 1 & 22 & 0.298 \\
\hline & $\begin{array}{l}\text { Refocus on } \\
\text { planning }\end{array}$ & 0.022 & 1 & 22 & 0.884 \\
\hline & Rumination & 0.742 & 1 & 22 & 0.398 \\
\hline & Catastrophizing & 0.156 & 1 & 22 & 0.697 \\
\hline & $\begin{array}{l}\text { Putting into } \\
\text { perspective }\end{array}$ & 0.928 & 1 & 22 & 0.346 \\
\hline & Positive refocusing & 0.047 & 1 & 22 & 0.830 \\
\hline & Positive reappraisal & 0.207 & 1 & 22 & 0.653 \\
\hline
\end{tabular}

Table 3. Box test to ensure the matrix homogeneity of variances of bullying clinical symptoms, anger control and emotional regulation.

\begin{tabular}{ccccc}
\hline Indicators & $\mathrm{F}$ & Degree offreedom 1 & Degree of freedom 2 & Significance level \\
\hline Values & 1.336 & 10 & 2313.944 & 0.205 \\
\hline
\end{tabular}

presented in Table 2 suggest that the assumption of the homogeneity of variances has been observed in all components. As can be seen, the results shown in Table 3 indicate that Box test is not significant $(\mathrm{P}=0.205, \mathrm{~F}=1.336)$. In other words, the matrix of co-variances is homogenous. So, multivariate analysis of covariance test can be performed.

To assess the research hypothesis indicating the effectiveness of dialectical behavior therapy in clinical symptoms of bully children (bullying, fighting and victimization), analysis of covariance method has been employed, whose results are as follows (Table 4):

As can be observed, the results obtained from comparing the posttest of bullying clinical symptoms in both groups with controlling the effect of the pretest suggest that after the bully boys' participation in dialectical behavior therapy sessions, their scores in bullying clinical symptoms compared to the control group have had a significant change. So, it can be concluded that dialectical behavior therapy has been effective in significantly reducing the scores of bullying clinical symptoms of bully boys (Table 5 ). 
Table 4. Results of covariance analysis for the dependent variable of bullying clinical symptoms.

\begin{tabular}{ccccccc}
\hline Variables & $\begin{array}{c}\text { Source of } \\
\text { changes }\end{array}$ & Df & F & P-value & $\begin{array}{c}\text { Impact } \\
\text { factor }\end{array}$ & $\begin{array}{c}\text { Statistical } \\
\text { power }\end{array}$ \\
\hline Bullying & Group & 1 & 18.624 & 0.000 & 0.453 & 0.983 \\
Fighting & Group & 1 & 19.018 & 0.000 & 0.500 & 0.985 \\
Victimization & Group & 1 & 11.878 & 0.003 & 0.385 & 0.905 \\
\hline
\end{tabular}

Table 5. Adjusted mean and standard deviation of bullying clinical symptoms.

\begin{tabular}{ccccc}
\hline Variable & $\begin{array}{c}\text { Dimensions of the } \\
\text { variable }\end{array}$ & Group & Adjusted mean & $\begin{array}{c}\text { Adjusted } \\
\text { standard } \\
\text { deviation }\end{array}$ \\
\hline \multirow{2}{*}{$\begin{array}{c}\text { Bullying clinical } \\
\text { symptoms }\end{array}$} & Fighting & Experimental & 17.83 & 1.94 \\
& & Control & 20.16 & 2.79 \\
& & Control & 10.16 & 1.46 \\
& Victimization & Experimental & 12.91 & 1.67 \\
\hline
\end{tabular}

As can be observed, the adjusted mean for the score of bullying clinical symptoms (bullying, fighting and victimization) in the experimental group is less than the control group.

In order to examine the research hypothesis suggesting the effectiveness of dialectical behavior therapy in anger control (external and internal anger control), analysis of covariance method has been used, whose results have been provided below (Table 6):

AS can be seen, the results obtained from comparing the posttest of external and internal anger control in both groups with controlling the effect of the pretest indicate that after the bully boys' participation in dialectical behavior therapy sessions, their scores in external anger control $(P=0.000, F=20.512)$ and internal anger control $(\mathrm{P}=0.000, \mathrm{~F}=23.184)$ compared to the control group have had a significant change. Therefore, it can be concluded that dialectical behavior therapy has been effective in significantly increasing the scores of external and internal anger control of bully boys (Table 7).

As can be observed, the adjusted mean for the score of anger control dimensions in the experimental group is higher than the control group.

In order to investigate the research hypothesis indicating the effectiveness of dialectical behavior therapy in emotional regulation (self-blame, blaming others, acceptance, refocus on planning, rumination, catastrophizing, positive refocusing, positive reappraisal and putting into perspective), analysis of covariance method has been applied, whose results have been presented below (Table 8):

As can be seen, the results obtained from comparing the posttest of positive emotional regulation dimensions (positive refocusing, positive reappraisal, putting 
Table 6. Results of covariance analysis for the dependent variable of anger control dimensions.

\begin{tabular}{ccccccc}
\hline Variables & $\begin{array}{c}\text { Source of } \\
\text { changes }\end{array}$ & Df & $F$ & P-value & $\begin{array}{c}\text { Impact } \\
\text { factor }\end{array}$ & $\begin{array}{c}\text { Statistical } \\
\text { power }\end{array}$ \\
\hline $\begin{array}{c}\text { External } \\
\text { anger } \\
\text { control }\end{array}$ & Group & 1 & 20.512 & 0.000 & 0.533 & 0.990 \\
$\begin{array}{c}\text { Internal } \\
\text { anger } \\
\text { control }\end{array}$ & Group & 1 & 23.184 & 0.000 & 0.563 & 0.995 \\
\hline
\end{tabular}

Table 7. Adjusted mean and standard deviation of anger control dimensions.

\begin{tabular}{cccc}
\hline Variable & Group & Adjusted mean & $\begin{array}{c}\text { Adjusted standard } \\
\text { deviation }\end{array}$ \\
\hline $\begin{array}{c}\text { External anger } \\
\text { control }\end{array}$ & Experimental & 23.82 & 0.489 \\
Internal anger & Control & 20.6 & 0.489 \\
control & Experimental & 22.76 & 0.456 \\
\hline
\end{tabular}

Table 8. Results of MANCOVA for the dependent variable of emotional regulation dimensions.

\begin{tabular}{ccccccc}
\hline Variables & $\begin{array}{c}\text { Source of } \\
\text { changes }\end{array}$ & Df & F & P-value & Impact factor & $\begin{array}{c}\text { Statistical } \\
\text { power }\end{array}$ \\
\hline $\begin{array}{c}\text { Positive } \\
\text { refocusing } \\
\text { Positive } \\
\text { reappraisal }\end{array}$ & Group & 1 & 44.501 & 0.000 & 0.712 & 1.000 \\
$\begin{array}{c}\text { Putting into } \\
\text { perspective }\end{array}$ & Group & 1 & 31.550 & 0.000 & 0.637 & 1.000 \\
$\begin{array}{c}\text { Refocus on } \\
\text { planning }\end{array}$ & Group & 1 & 25.375 & 0.000 & 0.635 & 0.996 \\
$\begin{array}{c}\text { Self-blame } \\
\text { Blaming others }\end{array}$ & Group & 1 & 73.051 & 0.000 & 0.839 & 1.000 \\
Acceptance & Group & 1 & 111.047 & 0.000 & 0.888 & 1.000 \\
Rumination & Group & 1 & 51.320 & 0.000 & 0.652 & 0.995 \\
Catastrophizing & Group & 1 & 57.342 & 0.000 & 0.804 & 1.000 \\
\hline
\end{tabular}

into perspective and refocus on planning) and negative emotional regulation dimensions (self-blame, blaming others, acceptance, rumination and catastrophizing) in both groups with controlling the effect of the pretest indicate that after the bully boys' participation in dialectical behavior therapy sessions, their scores in positive emotional regulation strategies (positive refocusing, positive reappraisal, putting into perspective and refocus on planning) and negative emotional regulation strategies (self-blame, blaming others, acceptance, rumination and catastrophizing) compared to the control group have had a significant 
change. Hence, it can be concluded that dialectical behavior therapy has been effective in significantly increasing the scores of positive emotional regulation and significantly decreasing the scores of negative emotional regulation of bully boys (Table 9).

As can be observed, the adjusted mean for the score of positive emotional regulation dimensions in the experimental group has increased relative to the control group and the adjusted mean for the score of negative emotional regulation dimensions in the experimental group has decreased compared to the control group.

\section{Discussion}

The present study aims to investigate the effectiveness of dialectical behavior therapy in clinical symptoms, anger control and emotional regulation of bully male students. The obtained results revealed that dialectical behavior therapy has a significant impact on clinical symptoms, anger control and emotional regulation of bully children.

The findings indicating the effectiveness of dialectical behavior therapy in clinical symptoms of bully children are consistent with the results obtained by researchers such as [24] [25] [26] since they also found that dialectical behavior therapy has an impact on clinical symptoms of bully children. In explaining the

Table 9. Adjusted mean and standard deviation of emotional regulation dimensions.

\begin{tabular}{|c|c|c|c|c|}
\hline Variable & $\begin{array}{c}\text { Dimensions of the } \\
\text { variable }\end{array}$ & Group & Adjusted mean & $\begin{array}{l}\text { Adjusted } \\
\text { standard } \\
\text { deviation }\end{array}$ \\
\hline \multirow{8}{*}{$\begin{array}{l}\text { Positive } \\
\text { emotional } \\
\text { regulation }\end{array}$} & \multirow{2}{*}{ Positive refocusing } & Experimental & 13.67 & 0.577 \\
\hline & & Control & 10.15 & 0.577 \\
\hline & \multirow{2}{*}{ Positive reappraisal } & Experimental & 13.70 & 0.574 \\
\hline & & Control & 10.21 & 0.574 \\
\hline & \multirow{2}{*}{$\begin{array}{l}\text { Putting into } \\
\text { perspective }\end{array}$} & Experimental & 14.58 & 0.531 \\
\hline & & Control & 10.76 & 0.531 \\
\hline & \multirow{2}{*}{$\begin{array}{l}\text { Refocus on } \\
\text { planning }\end{array}$} & Experimental & 13.14 & 0.416 \\
\hline & & Control & 10.43 & 0.416 \\
\hline \multirow{10}{*}{$\begin{array}{l}\text { Negative } \\
\text { emotional } \\
\text { regulation }\end{array}$} & \multirow{2}{*}{ Self-blame } & Experimental & 8.81 & 0.710 \\
\hline & & Control & 14.18 & 0.710 \\
\hline & \multirow{2}{*}{ Blaming others } & Experimental & 9.21 & 0.461 \\
\hline & & Control & 14.20 & 0.461 \\
\hline & \multirow{2}{*}{ Acceptance } & Experimental & 8.82 & 0.434 \\
\hline & & Control & 10.84 & 0.434 \\
\hline & \multirow{2}{*}{ Rumination } & Experimental & 11.09 & 0.355 \\
\hline & & Control & 13.81 & 0.355 \\
\hline & \multirow{2}{*}{ Catastrophizing } & Experimental & 11.47 & 0.397 \\
\hline & & Control & 13.73 & 0.397 \\
\hline
\end{tabular}


results of the present study indicating the effectiveness of dialectical behavior therapy in clinical symptoms of bully children, it can be said that according to [27], bullying and aggressive behaviors have a significant relationship with emotional dysregulation. Unlike the individuals who are victimized by bullying, bully people less suppress their emotions, especially negative emotions. They express their emotions with less intensity but use cognitive reassessment method and the severity of impulsivity for emotional actions is high in them and they express their negative emotions with more intensity. By creating a sense of fear and threat in others particularly the victims of their bullying, this state can always make them the target of these individuals' bullying. Based on the research evidence, bully students are physically strong and active and also very aggressive and adventurous. Thus, it seems logical that these individuals not to suppress their emotions and since the intensity of their emotional impulses is stronger, they have an internal tendency to dangerous acts and bullying. The lack of weak expression of positive emotions and conversely, strong expression of negative emotions in them cause that others regard them as violent people and submit to their bullying behaviors. This state can be considered as an amplification factor for the continuation of their bullying behaviors. With regard to the mentioned materials, through combining mindfulness exercises and emotion regulation with behavior therapy principles, dialectical behavior therapy teaches the students to observe their own physiological, mental and behavioral consequences with no judgment and to attempt for the unconditional acceptance of these behaviors since tolerance and acceptance of change lead to the experience of their positive emotions. On the other hand, by practicing these components, bully students can learn problem-solving and coping skills in everyday life and in dealing with the situations in which they have had difficulty in terms of emotions and disease symptoms, which is a sort of combination of behavioral and supportive therapy with cognitive problem-solving. In total, reduction in risky behaviors disturbing the quality of life, the ability to solve interpersonal conflicts and improve interpersonal relations of bully children in interaction with peers and parents, increased self-confidence and reduced daily unpleasant experiences, emotional instability and the ability to regulate and adjust negative emotions and their accompanying tension and anger as a result of training these skills cause bully students to enjoy better quality of life and hence, clinical symptoms of bullying are reduced in them.

\section{Conclusions}

The results of the studies conducted by [28] [29] [30] are congruent with the findings of the present study and accordingly, dialectical behavior therapy is significantly effective in the dimensions of anger control (internal and external anger control). Neacsiu, Rizvi and Linehan performed a study in 2010 entitled "Application of dialectical behavior therapy in the treatment of patients with personality disorder" and demonstrated that dialectical behavior therapy skills lead to reduced depression and increased anger control and have been specifi- 
cally effective in reducing self-injury and self-mutilation. Additionally, it can be stated that dialectical behavior therapy is effective in improving the severity of mood and emotions such as emotional instability. In fact, this treatment method provides the clients with a new instrument to express opinions and needs, determine the limitations and discuss the solution to the problem through training interpersonal skills. So, by teaching these skills, this therapy while supporting the relationships of these individuals with others help them respectfully continue these relationships over time. Therefore, dialectical behavior therapy is a treatment that has a clear structure and uses behavioral techniques and includes dialectical principles and techniques such as self-observation, meditation, exposure and dependency contract. Training these behavioral techniques can help in reducing the stability of destructive and aggressive behavior. Considering what has been mentioned so far, the aforesaid hypothesis is confirmed and it can be said that dialectical behavior therapy makes a significant impact on anger control.

Results of the present research indicating the effectiveness of dialectical behavior therapy in emotional regulation are consistent with the studies by [31] [32] [33]. In explaining the results of the present study indicating the effectiveness of dialectical behavior therapy in emotional regulation, it can be stated that dialectical behavior therapy can enhance the therapeutic efficacy due to its underlying mechanisms such as acceptance, increased awareness, the presence at the moment, judgment-free observation and refraining from experiential avoidance. Hence, an increase in psychological flexibility in dialectical therapy and creation of mindfulness-based thinking can promote the patient's ability to cope with difficult and anger-provoking situations. On the other hand, counteraction as one of the most important emotion regulation strategy based on dialectical behavior therapy encourages the patients to perform counteraction against negative emotions (anger). Further, a large number of patients withdraw with the earliest signs of emotional problems. So, assiduous attention to awareness of the present emotions is essential. "Counteraction" in the face of emotions helps the patients remain safe from falling to the bottom and indeed disruptive emotions when experiencing emotional problems [34] [35] [36]. Besides, mindfulness exercises in dialectical behavior therapy skills can help in emotional regulation and flexibility of attention by enhancing the individual's ability to turn the attention from what is unhelpful or ineffective (negative and disruptive emotions) to what is helpful and effective. Based on what has been said above, dialectical behavior therapy can affect the emotional regulation of students and thus, the mentioned hypothesis is confirmed.

\section{Limitation}

This research was faced with certain limitations including the inattention of some of the subjects participating in the study and also their dishonesty in answering the questionnaire. Moreover, their lack of interest and motivation was a factor that prevented them from appropriate cooperation. Given that therapeutic 
interventions need more time for being effective, the subject should be able to experience the provided trainings outside of the therapy sessions. In this study, the posttest was conducted immediately after completing the training course and it seems that the results should be interpreted with more caution. With regard to the findings of this study, it is recommended that the officials of correction and rehabilitation centers should consider the dialectical behavior therapy program in their long-term planning in order to reduce the frequency of occurrence and decrease the function of coercive behaviors in bully children and should take action to prevent the incidence of personal, family and social consequences following this problem and save in many human and financial costs imposed on the interested institutions and authorities.

\section{References}

[1] Fleming, L.C. and Jakobsen, K.H. (2009) Bullying and Symptoms of Depression in Chilean Middle School Students. Online Journal Public Health Inform, 79, 123-135.

[2] Kantor, A.M., Hamburger, M.E. and Lumpkin, C.D. (2014) Bullying Surveillance among Youths: Uniform Definitions for Public Health and Recommended Data Elements. Maternal and Child Health Journal, 16, 1625-1635.

[3] Goodman, M., Carpenter, D., Cheuk, Y., Tang, E., Avedon, J., Fernandez, N., Kathryn, A., Nicholas, J., Blair, S., Antonia, S., Triebwasser, J., Larry, J., Erin, A. and Hazlett, A. (2014) Dialectical Behavior Therapy Alters Emotion Regulation and Amygdala Activity in Patients with Borderline Personality Disorder. Journal of Psychiatric Research, 57, 108-116.

[4] Ahmed, C. and Braithwaite, U. (2004) Bullying and Victimization: Cause for Concern for Both Families and School. Social Psychology of Education, 7, 35-54. https://doi.org/10.1023/B:SPOE.0000010668.43236.60

[5] AkbariBaloutbongan, A. and Tale'pasand, S. (2015) Psychometric Properties of Harter Bullying Scale in Primary Schools in Semnan. Journal of Faculty of Health and Institute of Health Research, 12, 13-28.

[6] Aldo, A., Nolen-Hoeksema, S. and Schweizer, S. (2010) Emotion Regulation Strategies across Phychopath Logy: A Meta Analysis Review. Clinical Phychological Review, 30, 217-237.

[7] Alijanzadeh, M. (2012) Effectiveness of Dialectical Behavior Group Therapy (Based on Training the Skills) in Adolescents' Aggression. MA Thesis, University of Semnan, Semnan.

[8] Alilou, M.M. and Sharifi, M.A. (2011) Dialectical Behavior Therapy for Borderline Personality Disorder. Naroudis, Tehran.

[9] Ben-Porath, D. (2011) Dialectical Behavior Therapy for Depressed Older Adults: A Randomized Pilot Study. American Journal of Geriatric Psychiatry, 11, 33-45.

[10] Chan, H.Y., Lu, R.B., Tseng, C.L. and Chou, K.R. (2003) Effectiveness of the AngerControl Program in Reducing Anger Expression in Patients with Schizophrenia. Archives of Psychiatric Nursing, 17, 88-95.

[11] Fleischhaker, C.H., Bohme, R., Sixt, B., Bruck, C.H., Schneider, C. and Schulz, E. (2011) Dialectical Behavioral Therapy for Adolescents (DBT-A): A Clinical Trial for Patients with Suicidal and Self-Injurious Behavior and Borderline Symptoms with a One-Year Follow-Up. Child and Adolescent Psychiatry and Mental Health, 5,3 . 
http://www.capmh.com/content/5/1/3 https://doi.org/10.1186/1753-2000-5-3

[12] Gross, J.J. (2001) Emotion Regulation in Adulthood: Timing Is Everything. Current Directions in Psychological Science, 10, 214-219. https://doi.org/10.1111/1467-8721.00152

[13] Khodayari-fard, M., GholamaliLavasani, M., AkbariZardkhaneh, S. and Liyaqat, S. (2007) Investigating Psychometric Properties and Standardization of Spielberger State-Trait Anger Expression Inventory-2 among the Students of Tehran University. Research Project, Tehran University, Tehran.

[14] Klinke Chris, E.L. (2005) Life Skills. The Espandmehr Publication, Tehran.

[15] Leahy, L. (2012) Emotional Schemas, Emotion Regulation, and Psychopathology. International Journal of Cognitive Therapy, 5, 359-361. https://doi.org/10.1521/ijct.2012.5.4.359

[16] Linehan, M. and Dexter-Mazze, E. (2008) Dialectical Behavior Therapy for Borderline Personality Disorder. In: Barlow, D.H., Ed., Clinical Handbook of Psychological Disorders: A Step-by-Step Treatment Manual, Guiford Press, New York, 365-462

[17] McKay, M., Wood, J.C. and Brantley, J. (2007) The Dialectical Behavior Therapy Skills Workbook. New Harbinger, Oakland.

[18] Mcquillan, A., Nicastro, R., Guenot, F., Girard, M., Lissner, C. and Ferrero, F. (2011) Intensive Dialectical Behavior Therapy for Outpatient with Borderline Personality Disorder. Journal of Psychiatric Services, 56, 193-197.

[19] Nansel, T.R., Overpeck, M., Pilla, R.S., Ruan, W.J., Simons-Morton, B. and Scheidt, P. (2001) Bullying Behaviors among U.S. Youth: Prevalence and Association with Psychosocial Adjustment. The American Medical Association, 285, 2094-2100. https://doi.org/10.1001/jama.285.16.2094

[20] Neacsiu, A.D., Rizvi, S.H.L. and Linehan, M.M. (2010) Dialectical Behavior Therapy Skills Use as a Mediator and Outcome of Treatment for Borderline Personality Disorder. Behavior Research and Therapy, 48, 832-839.

[21] Nolen-Hoeksema, S., Wisco, B.E. and Lyubomirsky, S. (2008) Rethinking Rumination. Perspectives on Psychological Science, 3, 400-424. https://doi.org/10.1111/j.1745-6924.2008.00088.x

[22] Patchin, J.W. and Hinduja, S. (2011) Traditional and Nontraditional Bullying among Youth: A Test of General Strain Theory. SAGE Journals, 43, 727-751. https://doi.org/10.1177/0044118x10366951

[23] Perepletchikova, F., Axelrod, S.T., Kaufman, J., Rounsaville, B.J., Heather Douglas-Palumberi, H.D. and Miller, A.L. (2011) Adapting Dialectical Behaviour Therapy for Children: Towards a New Research Agenda for Paediatric Suicidal and Non-Suicidal Self-Injurious Behaviours. Child and Adolescent Mental Health, 16, 116-121. https://doi.org/10.1111/j.1475-3588.2010.00583.x

[24] Ragatz, L., Anderson, R., Fremouw, W. and Schwartz, R. (2011) Criminal Thinking Patterns, Aggression Styles, and the Psychopathic Traits of Late High School Ullies and Bully-Victims. Aggressive Behavior, 37 Reliability and Validity. Psychological Assessment, 4, 451-459.

[25] Videbeck, S.L. (2007) Psychiatric Mental Health Nursing. 3rd Edition, Lippincott Williams and Wilkins, Philadelphia.

[26] Wagner, A., Rizvi, S.L. and Harned, M.S. (2007) Application of Dialectical Behavior Therapy to the Treatment of Complex Trauma Related Problems: When One Case Formulation Not Fit All. Journal Trauma Stress, 20, 391-400.

https://doi.org/10.1002/jts.20268 
[27] Wallace, L.M., Masson, P.C., Safer, D.L. and von Ranson, K.M. (2014) Change in Emotion Regulation during the Course of Treatment Predicts Binge Abstinence in Guided Self-Help Dialectical Behavior Therapy for Binge Eating Disorder. Journal Eating Disorder, 2, 35. https://doi.org/10.1186/s40337-014-0035-X

[28] Yousefi, F. (2006) Assessing the Relationship between Cognitive Emotion Regulation Strategies with Depression and Anxiety in Students of Guidance Centers of Talented Students. Research Journal in the Domain of Exceptional Children, 6, 871892.

[29] Zamani, N., Farhadi, M., Jamilian, H.R. and Habibi, M. (2014) Effectiveness of Dialectical Behavior Therapy with the Reliance on the Components of Distress Tolerance and Emotional Regulation in Impulsive Behaviors and Explosive Anger. Journal of Arak Medical Sciences University, 17, 53-61.

[30] Rubin, K.H., Burgess, K.B., Dwyer, K.M. and Hastings, P.D. (2003) Predicting Preschoolers Externalizing Behaviors from Toddler Temperament, Conflict, and $\mathrm{Ma}-$ ternal Negativity. Development Psychology, 39, 164-176.

https://doi.org/10.1037/0012-1649.39.1.164

[31] Soler, J., Pascuala, J.C., Barrachina, J., Alvarez, E. and Perez, V. (2013) Double Blind Placebo Controlled Study of Dialectical Behavior Therapy Pluse Olanzapin for Borderline Personality Disorder. American Journal of Psychiatry, 162, 1221-1224.

[32] Soler, J., Valdepérez, A., Feliu-Soler, A., Pascual, J.C., Portella, M.J., Martín-Blanco, A., Alvarez, E. and Pérez, V. (2012) Effects of the Dialectical Behavioral Therapy-Mindfulnessmodule on Attention in Patients with Borderline Personality Disorder. Behaviour Research and Therapy, 50, 150-157.

[33] Stephanie, D., Amee, J., Seungmin, J. and Timothy, J. (2008) The Effective of Dialectical Behavioral Therapy Skills Use on Borderline Personality Disorder. Journal of Psychiatric Research, 22, 549-563.

[34] Stern, S.B. (1999) Anger Management in Parent Adolescent Conflict. The American Journal of Family Therapy, 27, 181-193. https://doi.org/10.1080/019261899262050

[35] Trupin, E.W., Stewart, D.G. and Boesky, L. (2002) Effectiveness of a Dialectical Behaviour Therapy Program for Incarcerated Female Juvenile Offenders. Child and Adolescent Mental Health, 7, 121-127.

[36] Vanden, B., Verhuel, R., Schippers, G.M. and Brink, W. (2002) Dialectical Behavior Therapy of Borderline Patient with and without Substance Use Problems Implementation and Long-Term Effects. Journal Addictive Behavior, 27, 911-923. 
Submit or recommend next manuscript to SCIRP and we will provide best service for you:

Accepting pre-submission inquiries through Email, Facebook, LinkedIn, Twitter, etc. A wide selection of journals (inclusive of 9 subjects, more than 200 journals)

Providing 24-hour high-quality service

User-friendly online submission system

Fair and swift peer-review system

Efficient typesetting and proofreading procedure

Display of the result of downloads and visits, as well as the number of cited articles Maximum dissemination of your research work

Submit your manuscript at: http://papersubmission.scirp.org/

Or contact ijcm@scirp.org 